\title{
Carcinossarcoma tireoidiano em um cão
}

\author{
Thyroid carcinosarcoma in a dog
}

\begin{abstract}
Aline Rodrigues ${ }^{I}$ Eduardo Kenji Masuda ${ }^{I}$ Maria Andréia Inkelmann ${ }^{I}$ Adriano Tony Ramos ${ }^{I}$ Brenda Maria Ferreira Prado Marques ${ }^{\text {II }}$ Tessie Beck Martins ${ }^{\text {II }}$ Glaucia Denise Kommers ${ }^{\text {III }}$
\end{abstract}

\begin{abstract}
Uma cadela de dois anos de idade, sem raça definida, apresentou disfagia e aumento de volume da região cervical ventral, correspondendo à região tireoidiana. Duas massas localizadas nessa região foram removidas cirurgicamente. O cão morreu poucos dias após a cirurgia e não foi necropsiado. O diagnóstico de carcinossarcoma de tireóide baseou-se na presença de componentes neoplásicos epiteliais e mesenquimais malignos, os quais foram confirmados pela reação imunoistoquímica positiva para citoqueratina $e$ vimentina, respectivamente. A origem tireoidiana foi confirmada pela imunomarcação positiva para tireoglobulina nas células epiteliais foliculares e no colóide. Este é um neoplasma raramente diagnosticado em cães.
\end{abstract}

Palavras-chave: neoplasmas da tireóide, tumor misto maligno, doenças de cães, imunoistoquímica, patologia veterinária.

\section{ABSTRACT}

A two year-old female mongrel dog was presented with dysphagia and focal swelling at the thyroid region. Two masses were surgically removed from that site. The dog died a few days after surgery and it was not submitted to necropsy. The diagnosis of thyroid carcinosarcoma was based on malignant epithelial and mesenchymal cell components of the neoplasm and confirmed by immunohistochemistry for cytokeratin and vimentin, respectively. The thyroid origin was confirmed based on the positive immunostaining for thyroglobulin on the follicular epithelial cells and colloid. This is a neoplasm rarely diagnosed in dogs.
Key words: thyroid neoplasms, malignant mixed tumor, diseases of dogs, immunohistochemistry, veterinary pathology.

Os tumores de tireóide ocorrem tanto em humanos (AL-SOBHI et al., 1997) quanto em animais domésticos, sendo descritos em cães, gatos e eqüinos (CAPEN, 2002; GRUBOR \& HAYNES, 2005). Nos cães, os carcinomas de tireóide são mais prevalentes que os adenomas, ao contrário do que ocorre nos gatos. Os tumores malignos de tireóide podem ser divididos de acordo com suas características microscópicas em carcinomas bem diferenciados (foliculares, papilares ou sólidos), pouco diferenciados (de células pequenas ou de células gigantes) e em carcinossarcomas (tumores mistos malignos) (CAPEN, 2002). Os carcinossarcomas de tireóide são raramente descritos em humanos (DONELL et al., 1987; COOPER \& BARKER, 1989; AL-SOBHI et al., 1997) e em cães (JOHNSON \& PATERSON, 1981; GRUBOR \& HAYNES, 2005). Eles são constituídos por células epiteliais foliculares malignas e por células malignas de origem mesenquimal com diferenciações cartilaginosa e/ou óssea (CAPEN, 2002). Assim como em humanos, em cães esses tumores são extremamente agressivos, localmente invasivos e metastatizam rapidamente para

IPrograma de Pós-graduação em Medicina Veterinária, Centro de Ciências Rurais (CCR), Universidade Federal de Santa Maria (UFSM), Santa Maria, RS, Brasil.

${ }^{\text {IIC }}$ urso de graduação em Medicina Veterinária, UFSM, Santa Maria, RS, Brasil.

IIILaboratório de Patologia Veterinária (LPV), Departamento de Patologia, Centro de Ciências da Saúde (CCS), UFSM, 97105-900, Santa Maria, RS, Brasil. E-mail: glaukommers@yahoo.com. Autor para correspondência. 
o pulmão, sendo as metástases constituídas por um ou por ambos os elementos carcinomatosos ou sarcomatosos (JOHNSON \& PATERSON, 1981; GRUBOR \& HAYNES, 2005).

Uma cadela de dois anos de idade, sem raça definida, apresentou disfagia e aumento de volume da região cervical ventral, correspondendo à região tireoidiana. Duas massas medindo 4,0 x 3,0 x 3,5 cm e 6,0 x 3,5 x 2,5cm, firmes ao corte, com múltiplos nódulos brancos cartilaginosos (Figura 1A), áreas hemorrágicas e calcificadas (massa com o maior diâmetro) foram removidas cirurgicamente e remetidas ao Laboratório de Patologia Veterinária (LPV-UFSM) para avaliação microscópica. Segundo o histórico clínico, exames radiográficos revelaram áreas radiopacas nos pulmões. Nove meses antes, o animal havia sido submetido à biópsia de tumor mamário, o qual não foi avaliado histologicamente. A cadela morreu poucos dias após a remoção das massas localizadas na região cervical e não foi submetida à necropsia.

As massas foram fixadas em formol $10 \%$, processadas e coradas rotineiramente para histopatologia. A técnica de imunoistoquímica (método da estreptavidina-biotina-peroxidase) foi realizada utilizando-se os seguintes anticorpos primários: policlonal antipancitoqueratina bovina (Dako) ${ }^{\mathrm{a}}$ na diluição de 1:2.000, monoclonal antivimentina humana - clone V9 (Dako) diluído a 1:100, e monoclonal antitireoglobulina humana - clone DAK-TG6 (Dako) ${ }^{\mathrm{a}}$ diluído a 1:200.

Histologicamente, a massa era composta principalmente por dois tipos celulares. Um era composto por células epiteliais neoplásicas formando estruturas foliculares de tamanhos variados, contendo material amorfo fortemente eosinofílico, interpretado como colóide (Figura 1B). Em algumas áreas, essas formações epiteliais eram pequenas, com ausência de lúmen. As células que compunham a parede folicular eram grandes, poliédricas e levemente pleomórficas. O núcleo era de redondo a oval, central, com pleomorfismo moderado, cromatina densa e nucléolo conspícuo e único. O citoplasma tinha aspecto granular eosinofílico e era abundante nos folículos pouco desenvolvidos, sendo homogêneo e escasso nos mais bem desenvolvidos. O número de figuras mitóticas variou de 0-2 por campo de maior aumento (400X). Havia múltiplos focos de necrose. Moderado infiltrado inflamatório, constituído principalmente por linfócitos e plasmócitos, também foi observado entre as formações foliculares neoplásicas. O segundo tipo celular era constituído por células mesenquimais distribuídas em feixes irregulares, com núcleos fusiformes, grandes e centrais (Figura 1B). O citoplasma era indistinto. Havia acentuado pleomorfismo celular e nuclear e o número de figuras mitóticas variou de 6-7 por campo de maior aumento (400X). Mitoses bizarras foram freqüentemente observadas. Áreas de diferenciação condróide e óssea foram observadas contíguas aos feixes de células mesenquimais pleomórficas (Figura 1C). Em algumas regiões, as estruturas foliculares estavam isoladas e circundadas pelas células do componente mesenquimal.

Na imunoistoquímica para citoqueratina, as células epiteliais dos folículos apresentavam forte imunomarcação (Figura 1D). Através desta técnica, os folículos e as ilhas de células epiteliais ficaram mais evidentes em meio ao componente mesenquimal do neoplasma. Na imunomarcação para vimentina, evidenciou-se a presença de extensas áreas constituídas por células com citoplasma escasso e fortemente marcadas (Figura 1E), correspondendo às áreas mesenquimais observadas na hematoxilinaeosina. Havia forte imunomarcação para tireoglobulina no material presente no lúmen de alguns folículos, a qual foi mais leve e granular no citoplasma das células foliculares neoplásicas (Figura 1F).

Os tumores de tireóide em cães geralmente ocorrem em animais adultos ou idosos, com uma média de idade de 9 anos, sendo rara a ocorrência desses tumores em animais jovens (CAPEN, 2002), como no caso deste relato. Em humanos, foi observado que há maior número de mulheres que desenvolvem carcinossarcomas de tireóide do que homens (ALSOBHI et al., 1997). Nos cães, dos seis casos encontrados na literatura até o presente momento, incluindo este relato, a relação fêmea:macho é de 2:1 (WELLS, 1901; MASON \& WELLS 1929; BUERGELT, 1968; GRUBOR \& HAYNES, 2005; JOHNSON \& PATTERSON, 1981). A maior prevalência deste neoplasma em fêmeas pode estar relacionada ao fato de que é observada a expressão de receptores hormonais (estrógeno e progesterona) no epitélio da tireóide (CAPEN, 2002).

Clinicamente, os caninos afetados podem apresentar dificuldade respiratória e de deglutição, em decorrência da compressão ou do deslocamento do esôfago e da traquéia pelo tumor (GRUBOR \& HAYNES, 2005). Em um dos casos anteriormente descritos em cães, carcinossarcoma tireoidiano foi associado a mixedema multifocal (JOHNSON \& PATERSON, 1981), sinal clínico associado ao hipotireoidismo em humanos (COTRAN et al., 2000). Tal alteração não foi observada no cão deste relato.

No presente caso, como a necropsia não foi realizada, não foi possível determinar se as áreas radiopacas observadas radiograficamente nos pulmões 

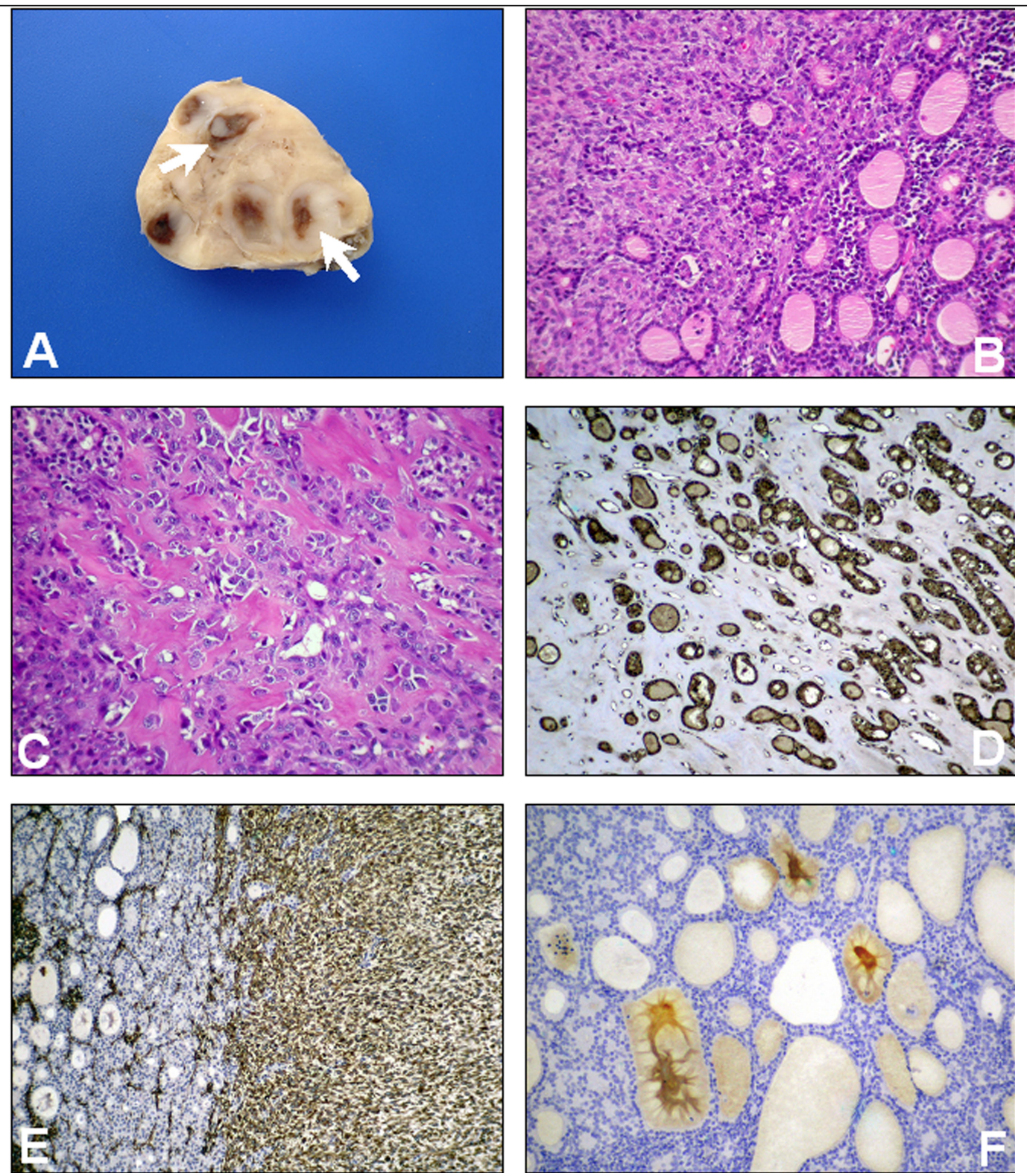

Figura 1 - Carcinossarcoma tireoidiano, cão. A) Aspecto macroscópico (material fixado) de uma das massas tumorais com formações cartilaginosas (setas) e áreas hemorrágicas (áreas marrom-escuras). B) Proliferação de células neoplásicas mesenquimais fusiformes entremeadas e formações epiteliais foliculares irregulares contendo colóide. HE, 200X. C) Células neoplásicas fusiformes circundando e incluídas em matriz osteóide. HE, 400X. D) Técnica de imunoistoquímica para citoqueratina. Observamse células epiteliais foliculares fortemente imunomarcadas. Método da estreptavidina-biotina-peroxidase, 100X. E) Técnica de imunoistoquímica para vimentina. Observam-se células fusiformes neoplásicas fortemente imunomarcadas (lado direito), contrastadas com formações epiteliais foliculares negativas para vimentina (lado esquerdo). Método da estreptavidina-biotina-peroxidase, 100X. F) Técnica de imunoistoquímica para tireoglobulina. O colóide no interior do lúmen folicular está fortemente imunomarcado, com fraca marcação das células epiteliais adjacentes. Método da estreptavidina-biotinaperoxidase, $200 \mathrm{X}$.

eram metástases do neoplasma tireoidiano. Deve-se ainda considerar que o cão deste relato tinha histórico de retirada de tumor mamário nove meses antes, o qual não foi avaliado microscopicamente, constituindo-se também numa possível fonte de metástase pulmonar, caso fosse um neoplasma mamário maligno. O padrão metastático dos carcinossarcomas provavelmente segue o mesmo padrão dos carcinomas de tireóide 
(JOHNSON \& PATERSON, 1981; CAPEN, 2002), sendo o pulmão o órgão mais freqüentemente afetado através da invasão dos ramos da veia tireoidiana (CAPEN, 2002). Nas metástases, os componentes epitelial e mesenquimal podem estar presentes em um mesmo foco ou em focos separados (VON SANDERSLEBEN \& HÄNICHEN, 1974), ou apenas um desses componentes pode ser observado (BUERGELT, 1968; JOHNSON \& PATERSON, 1981).

O diagnóstico de carcinossarcoma baseouse na presença de ambos os componentes epiteliais e mesenquimais malignos, os quais foram confirmados pela reação imunoistoquímica positiva para citoqueratina e vimentina nas células neoplásicas, respectivamente. A citoqueratina é o filamento intermediário que caracteriza as células epiteliais de forma específica; as células mesenquimais expressam o filamento intermediário vimentina, o qual não é tipo celular específico (CERILLI \& WICK, 2006). A imunoistoquímica positiva para tireoglobulina foi de extrema importância para a confirmação da origem tireoidiana do neoplasma, descartando-se os tumores mistos malignos de glândula salivar (HEAD et al., 2002) e as metástases de carcinossarcomas mamários (MISDORP, 2002) do diagnóstico diferencial.

O prognóstico dos carcinossarcomas tireoidianos em animais é de reservado a desfavorável, pois esses tumores apresentam um comportamento bastante agressivo, caracterizado por crescimento rápido, invasão dos tecidos adjacentes e metástases freqüentes (CAPEN, 2002; GRUBOR \& HAYNES, 2005).

\section{FONTES DE AQUISIÇÃO} Estados Unidos.

DAKOCytomation, Carpinteria, Califórnia,

\section{AGRADECIMENTOS}

Os autores agradecem o apoio técnico de Ailton Pinto de Quadros, do Depto. de Patologia (UFSM), na realização da técnica de imunoistoquímica para tireoglobulina. Os co-autores B.M.F.P. Prado Marques e T.B. Martins são bolsistas PIBIC/ CNPq.

\section{REFERÊNCIAS}

AL-SOBHI, S.S. et al. Management of thyroid carcinosarcoma. Surgery, v.122, p.548-542, 1997.
BUERGELT,C-D. Mixed thyroid tumors in two dogs. Journal of American Veterinary Medical Association, v.152, p.1658-1663, 1968.

CAPEN, C.C. Tumors of the endocrine gland. In: MEUTEN, D.J. Tumours in domestic animals. 4.ed. Ames, Iowa: Iowa State, 2002. Cap.13, p.607-696.

COOPER, K.; BARKER, E.M. Thyroid carcinosarcoma. South African Journal of Surgery, v.27, p.192-193, 1989.

CERILLI, L.A.; WICK, M.R. Immunohistology of soft tissue and osseous neoplasm. In: _____. Diagnostic immunohistochemistry. 2.ed. China: Elsevier, 2006. Cap.3, p.65-120.

COTRAN, R.S. et al. O sistema endócrino. In: Robbins pathologic basis of diseases. 6.ed. Rio de Janeiro: Guanabara Koogan, 2000. Cap.26, p.1003-1047.

DONELL, C.A. et al. Thyroid carcinosarcoma. Archives of Pathology and Laboratory Medicine, v.111, p.1169-1172, 1987.

GRUBOR, B.; HAYNES, J.S. Thyroid carcinosarcoma in a dog. Veterinary Pathology, v.42, p.84-87, 2005.

HEAD, K.W. et al. Tumours of the alimentary tract. In: MEUTEN, D.J. Tumours of domestic animals. 4.ed. Ames, Iowa: Iowa State, 2002. Cap.8, p.401-481.

JOHNSON, J.A.; PATTERSON, A.M. Multifocal myxedema and mixed thyroid neoplasm in a dog. Veterinary Pathology, v.18, p.13-20, 1981.

MASON, R.; WELLS, H.G. On the occurrence of true mixed carcinomatous and sarcomatous tumors (sarcocarcinoma) with report of mixed carcinoma-chondrosarcoma of the thyroid of a dog. American Journal of Cancer, v.13, p.207-210, 1929.

MISDORP, W. Tumours of the mammary gland. In: MEUTEN, D.J. Tumours of domestic animals. 4.ed. Ames, Iowa: Iowa State, 2002. Cap.11, p.575-606.

VON SANDERSLEBEN, J.; HÄNICHEN, T. Tumours of the thyroid gland. Bulletin of the World Health Organization, v.50, n.1-2, p.35-42, 1974.

WELLS, H.G. Multiple primary malignant tumors: report of a primary sarco-carcinoma in the thyroid of a dog, with mixed sarcomatous and carcinomatous metastases. Journal of Pathology and Bacteriology, v.7, p.357-367, 1901. 